\title{
How to Innovate the Service Design of Leisure Farms: The Innovation of Sustainable Business Models
}

\author{
Mengyi Lin ${ }^{1}$, Fu-Yuan $\mathrm{Li}^{2, *}$ and $\mathrm{Zhe} \mathrm{Ji}^{3}$ \\ 1 The Graduate Institute of Design Science, Tatung University, Taipei 104, Taiwan; d10517014@ms.ttu.edu.tw \\ Department of Industrial Design, Tatung University, Taipei 104, Taiwan \\ 3 School of Design Art, Xiamen University of Technology, Xiamen 361024, China; jizhe@xmut.edu.cn \\ * Correspondence: richardlee@gm.ttu.edu.tw
}

Received: 1 June 2020; Accepted: 28 June 2020; Published: 29 June 2020

\begin{abstract}
There is extensive academic literature about service satisfaction, business performance analysis, and management research of leisure farms, but there are still many problems and room for development on how to create customer journey maps for diversified leisure farms and also on service innovation opportunities. Leisure agricultural tourism is now facing diversified business challenges, and thoughts on service design as well as methods and tools contribute to the innovation of sustainable business models. By exploring customers' touchpoints on leisure farms and their core motivations to visit the farm, this paper proposes a method to integrate the application of target tools of touchpoints into the customer journey map and shows the service design framework of leisure farms' management and organization. Finally, this paper puts forward five key requirements on touchpoints in leisure farms' service innovation, so as to achieve reasonable resource deployment of marketing mix and promote the sustainable development of leisure farms.
\end{abstract}

Keywords: leisure farms; customer journey map; service design; customer touchpoints; core motivation

\section{Introduction}

\subsection{Research Question}

With the vigorous development of leisure agricultural tourism, the destination which used to be a place for crop planting and processing in traditional agriculture in tourists' minds has now evolved into a more general idea and a new type of diversified agricultural production that tourists can not only enjoy through sightseeing, fruit picking, farming, understanding farmers' lives, and finding entertainment in the countryside, but also live on the farm for vacation and leisure. Many scholars have mentioned that agricultural diversification is an inevitable trend of agricultural tourism development [1-3]. Farmers have been encouraged to join agricultural tourism through diversified ways. The leisure farm, which combines agriculture with tourism, is a comprehensive and diversified business organization. It will involve a variety of services such as travel planning, local transportation, accommodation, food, and leisure activities.

Such diversification not only changes the role of farmers, but also brings new challenges to them. It requires farmers to master the ability to develop new skills in order to improve their competitiveness and also improve the governance structure required by diversification. The process of farmers' innovation and diversification is very complex. It requires the collaboration and combination of local and expert knowledge, the ability to build networks and extract value from these networks, and personal motivation and adjustment to achieve business objectives [4]. Farmers keen to maintain and plan specific agricultural or agricultural identities are not always easy to establish tourist attractions on their farms [5]. 


\subsection{Research Method and Scope}

Agricultural tourism is a diversified industrial form. It not only involves agricultural planting, nurturing, and harvesting, but also involves the content of industrial conversion-that is to say, the conventional part of agriculture needs to be converted into tourism-related on the basis that the agricultural part can be operated normally and combining guidance and contents that can assist agricultural tourism, so as to truly increase the added value of agriculture in agricultural tourism, and, at the same time, provide support for the sustainable development of agricultural tourism. In addition, based on the different operating contents and modes of different farms, it can be modeled as a differentiated content in agricultural tourism, which is more conducive to advertising and marketing and to triggering the industrial additional value and potential of development based on agricultural tourism. This study consists of three stages of research: the first stage is the depiction of the customer journey map of the farm; the second stage is the core motivation of tourists to visit leisure farms; and the last stage is the interaction among touchpoints, visiting motivations, tourists' demands and expectations, the goals of touchpoints, and the innovative design for opportunities, so as to improve the service design of leisure farms and make innovations in sustainable business models of leisure farms.

\section{Literature Review}

Prendeville and Bocken put forward that service design can be the core factor of business mode innovation [6]. Innovation can become an important driving force for the growth of tourism industry [7]. Service innovation is a new resource that can be used by customers through interaction with customers, requiring providers and customers to participate and interact at varying degrees [8]. Tourism is a service-oriented industry, in which success always ultimately depends on the experience of the customer. Therefore, tourism managers must consider new methods of designing and analyzing destination experiences. In addition, service quality has been set as an important economic driving force in the tourism industry, and in terms of tourism service quality, keywords related to customer satisfaction have been paid more and more attention to [9]. Traveling satisfaction refers to the positive feelings or pleasures obtained after experiencing or consuming any travel-related products or services [10], which also includes evaluating the traveling experience or tourism products according to tourists' motivations [11]. Meanwhile, in marketing and designing, experience is an important factor for understanding users [12]. Regarding customers' satisfaction degree as the goal which is decomposed into several key results, the realization of the goal is derived according to the achievement of the key results. This involves the design, establishment, and implementation of a complete system.

Stickdorn put forward that using the process and method of service design is helpful to establish an organization and deeply and comprehensively understand the needs of creating meaningful experience with tourists [13], which has obvious potential to help the tourism industry develop an excellent tourism experience. In service design, the customer journey map (CJM) is an effective management tool for academia and practitioners to understand the customer experience of an organization [14]. Generally speaking, the customer journey map can reflect the real feedback of customers' satisfaction and combine the visiting route with feedback system, which goes beyond the traditional methods to conduct research and evaluation on customers and bridges the distance between enterprises and customers [15]. This tool creates a virtuous circle between enterprises' future plans and customers' satisfaction. Integrating motivation with existing tools such as comparison between designed journey plans and customers' journey portrayal will be of great help to service designers when they begin to address important issues in society [16]. The CJM lists all the touchpoints that may be encountered in the service. Customer touchpoints are comprised of human, product, service, communication, space, and electronic interactions, which make up the connection point bridging businesses and consumers together during the consumer experience period [17]. "Customers' touchpoint" is the core of both of our farm service design and its implementation. According to Dhebar in the research on the structure of customers' touchpoints, on April 7, 2012, there were nearly 500,000 references when searching the keyword "customer touchpoints" on Google [17]. On May 16, 2018, the number reached 4.3 million, 
and almost all of them could be traced back to the publishing website of marketing consultants. As of June 10, 2020, this number has reached 12.7 million. However, few studies have been done on the development of leisure farms' touchpoints. In the past, there were many academic and management literatures on service satisfaction and performance analysis of leisure farms, but some puzzles on how to create a diversified leisure farm CJM and service innovation opportunities still remain.

By setting different access forms and access contents at different touchpoints, the information conducive to farm management can be subtly conveyed to consumers through touchpoints, and customers' feedback on the contents of the customer journey map can be effectively collected, which can be used as an important reference for the improvement of touchpoint settings in the future. The design of each touchpoint is a channel to achieve the key results, through which it is possible to clarify the difficulty of achieving the ultimate goal and the properness of the program. Therefore, the design of the customer journey map is an important tool to determine the feasibility of agricultural tourism.

Tourism motivation has been extensively studied in the field of natural tourism and ecotourism, which can provide crucial information for tourist management, marketing strategies, and product development [18]. In the past, most scholars' research on tourism motivations mainly included: to experience new things, to meet different people, to learn different cultures, to learn new skills, to stay away from the pressure of daily life, to exercise, to show off to others, to get along with family and friends and visit amazing places, to stay away from the crowd, to get close to nature, to relax, to promote intimacy and enjoy the nature, to enjoy the pastoral scenery of the countryside, to temporarily stay away from the living environment in the city, to get rid of the tension from daily life, to seek relaxation, and to enjoy a peaceful life, warm atmosphere, landscape, and nature-related activities [19-22]. Tourism motivation is a driving force that drives tourists to meet their social and psychological needs. It is also the real reason why tourists engage themselves in recreational activities [23]. Baloglu and McCleary thought that tourism motivation will affect destination image formation and destination selection [24]. Therefore, in addition to identifying the most relevant touchpoints provided by leisure farms, it is also important to understand the driving forces and motivations of visitors to leisure farms. It is the beginning of leisure farm service design to have a thorough insight into tourists' needs, think from their perspectives, and understand their needs and psychology.

Our goal is to develop an effective framework of service design for the public and for small and medium-sized enterprises. Through the connection between the core motivation of tourists and service design, we can identify the touchpoints that may help small and medium-sized enterprises to achieve operational efficiency and face profitability challenges. We integrate the whole process of customer behavior, from planning to the completion of the tour into a moving line, decompose all the farm-related contents that the customer may encounter in the moving line, find the achievable output method in each point-to-point interaction, and establish a back-end mechanism to collect customers' feedback at the same time, making touchpoints a mechanism for better experience and truly allowing customers to provide us feedback on touchpoints from the perspective of participants. In this way, the theme and market differentiation of the leisure farm can be more targeted, and the characteristics of the farm's service design can be more effectively highlighted. Meanwhile, its core competitiveness can be strengthened, and the concept suitable for the farm will be created and merged into a name card of agricultural tourism, realizing brand management, personalized output, and even the construction and management of local IP, as well as enhancing the influence of the farm and its location from the perspective of economic and social benefits. The realization of all these mentioned above is based on figuring out the marketable differences and competitive experience that the farm can provide.

\section{3 Steps Concept Model Building for the Service Design of Leisure Farms}

This study proposes an innovative approach to the service design of leisure farms through three stages: 
In the first stage, the customer touchpoints applicable to most leisure farms are summarized through the customer journey maps of 20 farms.

In the second stage, the core motivations of tourists to visit leisure farms are confirmed.

In the third stage, combining the touchpoints applicable to most leisure farms and the core motivations of tourists visiting leisure farms, a new framework of the service design of leisure farms is proposed.

Such a tool can effectively improve tourists' experiences of agricultural tourism by regarding customers as a dynamic point in the overall planning of the agricultural tourism, which truly considers various possibilities of the movement of the moving line and its complementary function when touchpoints are not reached in time, systematically constructs the path of customers' behaviors, implements instructional sections of guidance, and specifies the realization of each touchpoint, so as to encourage tourists to revisit, increase the purchase of agricultural products, and promote sustainable farm management.

\subsection{The First Stage: A Description of Leisure Farm CJM}

According to Stickdorn [13], a leisure vacation involves a complex service ecosystem including not only the service related to stakeholders, but also the entire ecosystem that tourists face at a particular destination. The focus of service design is to identify the touchpoints that are most relevant to the provision of service and map out how these different touchpoints can provide customers with consistent top-level service [16]. Customer touchpoints of leisure farms are the focus in space, facilities, service, social media communication, and new media marketing between tourists and farms, which constitutes the CJM of leisure farms during the whole visiting experience, including stages before, during, and after service. Among different stages of leisure farms' CJM, the touchpoints of pre-service customer experience may include friends' introduction, website visits, social group discussion, telephone service consultation, etc. Touchpoints experienced during the service are guide signs on farms, the ticket house at the farm gate, parking lots, interaction with staff and owners, participation in farm activities, purchase of farm gifts, etc. Possible touchpoints after service include pictures that customers post after visiting farms on social media, recommendations to relatives and friends, receiving express packages of purchased farm products, etc. There are three stages in how to present service innovation of touchpoints to achieve sustainable business development.

In summary, in the first stage, the characteristics of the sample objects of this research were investigated on the spot, and the focus was on the leisure farms in Taiwan. In terms of leisure agriculture, Taiwan has its inherent advantages, for Taiwan used to be an agricultural society traditionally. After the decline of agriculture in the 1980s, farmers in Taiwan began to seek new opportunities to make a living, and the government started to promote the development of tourism agriculture. After long-term efforts, Taiwan's tourism agriculture has now formed its own system with a certain scale of business and a lot of popularity, which provides guidance for farms in other regions. This study adopted "visiting and in-depth observing" as researching methods by focusing on the leisure farms in the northern, central, and southern parts of Taiwan and selecting 20 leisure farms of seven different types with Facebook scores above 4.0 ( 5 points as maximum). The seven types include flower and fruit picking, ecological education, gardening, dairy producing, arts and cultural, etc. We completed the customer journey map of each farm and compared, analyzed, and integrated them from the point of view of the tourists. According to different farm characteristics, we found the touchpoints common to leisure farms, from which we drew a comprehensive model of customer touchpoints to build an effective model applicable to most leisure farms in service design.

Due to the differences among each farm and different quality of services, for the results of field research in the past [25], the number of touchpoints was as low as 11 and as high as 29. However, there were some shared touchpoints among pre-service, during-service, and post-service touchpoints, such as word-of-mouth, others' recommendations, or recommendations to others, hotline service, mobile staff, online comments, etc. According to the scale and business model of different leisure farms, 
the number of touchpoints can be different. On this basis, this study summarizes effective touchpoints applicable to most leisure farms in service design, assuming that they are all the touchpoints that every leisure farm may encounter. Due to the diversity of leisure farms compared with other traditional tourism and the complexity of various farm themes and additional services, in order to focus on the touchpoints of leisure farms macroscopically, sub-touchpoints in every single service will not be discussed in this study. For example, touchpoints such as ordering, waiting for meals, and paying bills in theme restaurant service are all generally regarded as the touchpoints of theme restaurant service. With the focus on core touchpoints and important touchpoints, and after our analysis and classification of touchpoints in 20 farms of seven different types, Figure 1 shows all the touchpoints that may be encountered during the farm-experiencing week. There are 3 pre-service touchpoints in general, 30 in-service ones, and 3 post-service ones (Table 1).

\subsection{The Second Stage: The Core Motivation of Tourists When Choosing Leisure Agricultural Tour}

The setting of touchpoints involves a relatively comprehensive consideration of the customers' demands, and at different stages of traveling, tourism motivations reveal the true and potential demands of tourists. Understanding tourists' demands can help transmit information and instructions about travel routes and contents in accordance with tourists' demands. Therefore, it is necessary for us to understand the motivations and expectations of tourists on leisure farms and think from their perspectives based on tourists' core motivations and farm owners' expectations on touchpoints, so as to provide better travel experiences and propose more satisfactory touchpoints of farm services. On the basis of perfecting the equipment of leisure farms, new methods and contents which help better communicate with customers can be implemented, and all touchpoints can be turned into the trigger points for leisure farm management, so as to optimize the management of leisure farms. In the past, scholars have conducted a lot of research on tourists' motivations, and they have clearly pointed out the factors that make tourists want to visit a certain tourist destination. Based on their research and the characteristics of each sample farm, it is possible to find problems in a targeted manner and formulate solutions and specific methods to solve the problems through touchpoints.

The second stage of the study was conducted through literature review and an interview with 20 people of different ages and incomes from different places as a pre-test. We tried to understand the leisure motivations of tourists. Through a questionnaire survey, we found the core factors that affect tourists' decisions on leisure farms and the most important factors that affect leisure farm visits. We comprehensively collected motivations that prompted tourists to visit leisure farms and obtained 45 different answers. Later, we used these 45 options to conduct online questionnaires about tourists' visiting motivations by seven-point Likert scale and ordinal scale in order to compare the core factors that may affect visitors' intention to visit leisure farms and find out which factors are the most important in deciding whether to visit the farm. We received a total of 417 valid samples and found the top 10 motivations that affect tourists' decisions on leisure farm visits (Figure 1). From the results in the past [25], we sorted out the core motivations; they are: 1. get close to nature and relax themselves on the farm; 2 . taste local food on the farm; 3 . enjoy the beautiful countryside scenery of the farm; 4. spend time with friends and family; 5 . experience life on the farm; 6. participate in outdoor recreation activities; 7 . highly recommended by friends and family members to the farm with very good reputation; 8. perfect facilities on the farm; 9. parties and social gathering; and 10. experience farm culture and atmosphere. The results of the questionnaire also showed that family members' and friends' recommendations and online information were two main sources to learn more about the farm, and the ratio reached $71.94 \%$ and $46.28 \%$, respectively. The results about the concerning factors showed that people pay most attention to food on the farm, followed by culture, and then accommodations and facilities. These results give directions to the design of farm service touchpoints. 


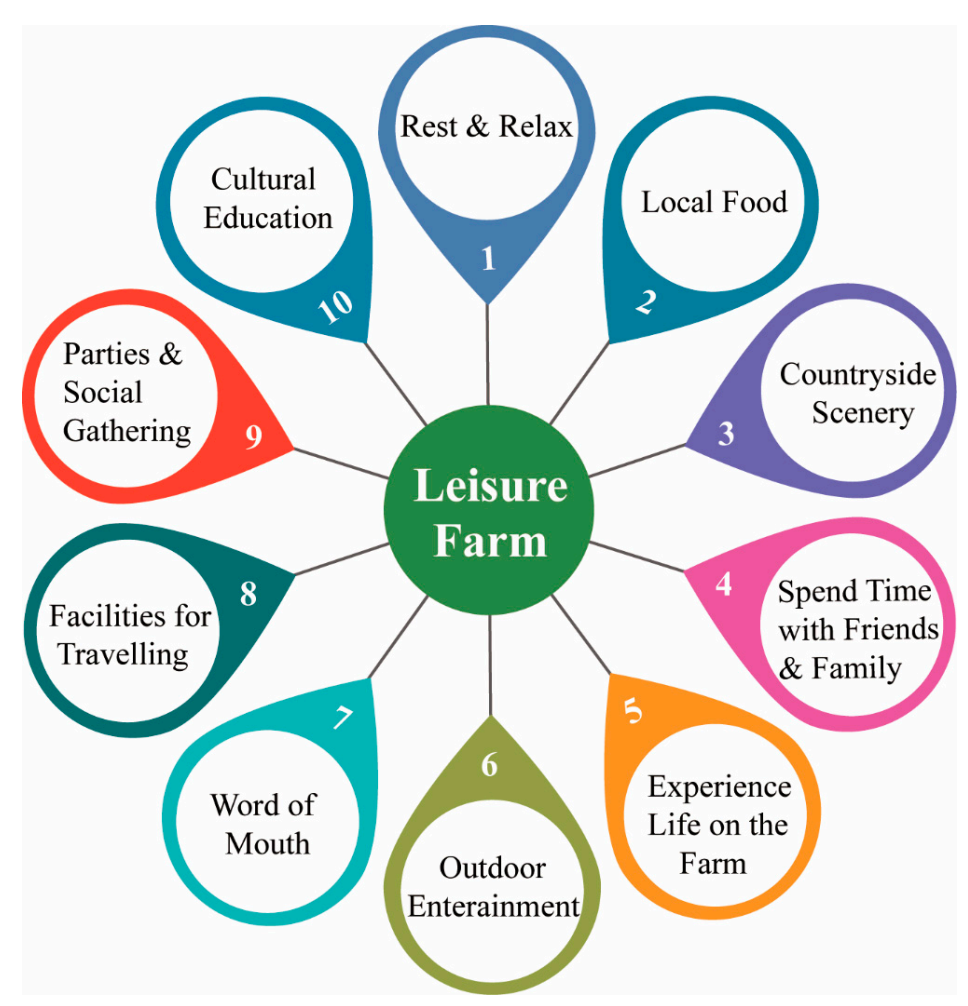

Figure 1. 10 core motivations that affect tourists' vacation to leisure farms.

Table 1. Touchpoints of customer journey on leisure farms.

\begin{tabular}{|c|c|c|}
\hline Periods & Touch $_{1}$ & \\
\hline \multirow{2}{*}{ pre-service } & word of mouth: others' recommendations & information on website \\
\hline & telephone consultation with customer service staff & \\
\hline \multirow{15}{*}{ in-service } & pickup service & guiding signs for entrance \\
\hline & activity advertising & tickets \\
\hline & parking lots & sanitary facilities \\
\hline & barrier-free facilities & accommodation \\
\hline & bicycle renting & conference rooms \\
\hline & photograph shooting area & recreational pavilions \\
\hline & landscaping design & tourist service center \\
\hline & mobile staff & tour guidance \\
\hline & outdoor activity teaching & shows and performance \\
\hline & entertaining area for children & getting close to animals \\
\hline & farm picking activities & experiencing producing agricultural products \\
\hline & DIY activities & outdoor picnic area \\
\hline & BBQ area & camping \\
\hline & outdoor selling area & theme restaurants \\
\hline & gift stores & exits/parking lots \\
\hline \multirow{2}{*}{ post-service } & online stores & online comments \\
\hline & word of mouth: recommending the farm to others & \\
\hline
\end{tabular}

\subsection{The Third Stage: Target Tools for Touchpoints}

After clearly knowing the tourist touchpoints and core motivations of leisure farms, we needed to use service design tools to achieve innovative design of touchpoints. Dhebar compared touchpoints to a building in which floors, rooms and other architectural elements are gradually added [17]. In view of 
this, for leisure farms, the touchpoints should be combined with the farm's ecological environment, plants, breeding industry, and entertainment activities to form a unique system. For operating organizations, all the touchpoints are a complementary combination as a whole instead of a single existence, because each touchpoint is related to the overall satisfaction degree. In the innovative service design of leisure farms, it should be a kind of thinking mode of the overall business objectives, and its satisfaction degree affects tourists' decisions both directly and indirectly, which determines the achievement of leisure farm management. Although the service blueprint shows the coordinate scheme that the organization consisting of each touchpoint and stakeholders needs to confront, farm managers and staff have limited ability to understand the complexity and interdependency within the service system. Additionally, they do not understand the cross-functional linkage between service systems of each touchpoint. This study uses touchpoint target tools to address these limitations, clearly demonstrates the benefit goals that each functional touchpoint may have for farm operators, and seeks innovative opportunities from that. In other words, the target tool of touchpoints adopted in this study establishes a behavioral reference system for farm managers and employees, which helps them conduct self-checking and self-review in work and can effectively assist the management and operation of leisure farms.

Due to the complex diversity of leisure farms and different resource deployment between different farms, we could not draw the framework of service design according to a standard timeline. Instead, we integrated tourists' core motivations and expectations with the target tools of touchpoints and conducted innovative design of CJM touchpoints, both of which constituted a desired service design framework between farm owners and tourists (Table 2). 
Table 2. Service design framework for leisure farms.

\begin{tabular}{|c|c|c|c|c|c|}
\hline & Touchpoints & Visiting Motivations & Tourists' Needs and Expectations & Goals of Touchpoints & Innovative Design of Opportunity Points \\
\hline \multirow{3}{*}{ pre-service } & $\begin{array}{l}\text { word of mouth: others' } \\
\text { recommendations }\end{array}$ & \multirow{3}{*}{$\begin{array}{l}\text { word of mouth and others' } \\
\text { recommendations }\end{array}$} & \multirow{3}{*}{$\begin{array}{l}\text { to find a suitable leisure } \\
\text { farm quickly }\end{array}$} & \multirow{3}{*}{$\begin{array}{l}\text { to let tourists decide to visit the farm } \\
\text { with expectations }\end{array}$} & \multirow{3}{*}{$\begin{array}{l}\text { a. developing online applications } \\
\text { b. encouraging people to share visiting experience with others on social media } \\
\text { c. develop media for sharing experience } \\
\text { d. complete farm map and information of tour planning }\end{array}$} \\
\hline & information on website & & & & \\
\hline & $\begin{array}{l}\text { telephone consultation with } \\
\text { customer service staff }\end{array}$ & & & & \\
\hline \multirow{29}{*}{ in-service } & pickup service & \multirow{10}{*}{ tourism facilities } & \multirow{4}{*}{$\begin{array}{l}\text { to reach the farm easily and know } \\
\text { the activities on the farm }\end{array}$} & \multirow{4}{*}{$\begin{array}{l}\text { to let tourists participate in more interactive activities } \\
\text { so that they can share their experience with others, to } \\
\text { stimulate consumption on the farm and farm product } \\
\text { sales, and to collect tourists' information for } \\
\text { future contact }\end{array}$} & \multirow{4}{*}{$\begin{array}{l}\text { a. guiding signs } \\
\text { b. advertising strategy } \\
\text { c. ticket booking } \\
\text { d. recommended visiting routes }\end{array}$} \\
\hline & guiding signs for entrance & & & & \\
\hline & activity advertising & & & & \\
\hline & tickets & & & & \\
\hline & parking lots & & \multirow{6}{*}{$\begin{array}{l}\text { convenient and perfect } \\
\text { public facilities }\end{array}$} & \multirow{6}{*}{$\begin{array}{l}\text { public facilities should meet tourists' demands and } \\
\text { provide them with a good visiting experience }\end{array}$} & \multirow{6}{*}{$\begin{array}{l}\text { a. stylized parking lots } \\
\text { b. personalized sanitary facilities } \\
\text { c. differentiated accommodation space }\end{array}$} \\
\hline & sanitary facilities & & & & \\
\hline & barrier-free facilities & & & & \\
\hline & accommodation & & & & \\
\hline & bicycle renting & & & & \\
\hline & conference rooms & & & & \\
\hline & photograph shooting area & \multirow{3}{*}{$\begin{array}{l}\text { relaxation and to enjoy } \\
\text { countryside scenery }\end{array}$} & \multirow{3}{*}{$\begin{array}{l}\text { to relieve themselves, get relaxed, } \\
\text { and have unforgettable memories }\end{array}$} & \multirow{3}{*}{$\begin{array}{l}\text { to let tourists write comments on social media to } \\
\text { increase the farm's popularity }\end{array}$} & \multirow{3}{*}{$\begin{array}{l}\text { a. more space for relaxation } \\
\text { b. facilities for interactive activities } \\
\text { c. subtly implanting the farm brand on social media to increase the popularity of } \\
\text { the farm }\end{array}$} \\
\hline & recreational pavilions & & & & \\
\hline & landscaping design & & & & \\
\hline & tourist service center & \multirow{4}{*}{$\begin{array}{l}\text { customer service/cultural } \\
\text { education on the farm }\end{array}$} & \multirow{4}{*}{$\begin{array}{l}\text { to solve problems in time, } \\
\text { be familiar with the farm, and } \\
\text { acquire knowledge }\end{array}$} & \multirow{4}{*}{$\begin{array}{l}\text { to solve problems for tourists during visiting, leave } \\
\text { them a good and deep impression, and lay foundation } \\
\text { for farm product sales }\end{array}$} & \multirow{4}{*}{$\begin{array}{l}\text { different routes to the farm, information about the farm products, online stores, } \\
\text { and tour guidance }\end{array}$} \\
\hline & mobile staff & & & & \\
\hline & tour guidance & & & & \\
\hline & $\begin{array}{l}\text { outdoor guidance and activity } \\
\text { teaching }\end{array}$ & & & & \\
\hline & shows and performance & \multirow{6}{*}{$\begin{array}{l}\text { outdoor entertainments/to } \\
\text { experience life on the farm }\end{array}$} & \multirow{6}{*}{$\begin{array}{l}\text { to hang out with families, } \\
\text { experience life on the farm, } \\
\text { and strengthen } \\
\text { interpersonal relationships }\end{array}$} & \multirow{6}{*}{$\begin{array}{c}\text { to leave tourists a piece of good experience and attract } \\
\text { more visitors }\end{array}$} & \multirow{6}{*}{$\begin{array}{l}\text { a. activities requiring several people to join in } \\
\text { b. theme activities associated with season and festivals }\end{array}$} \\
\hline & entertaining area for children & & & & \\
\hline & getting close to animals & & & & \\
\hline & farm picking activities & & & & \\
\hline & $\begin{array}{l}\text { experiencing producing } \\
\text { agricultural products }\end{array}$ & & & & \\
\hline & DIY activities & & & & \\
\hline & outdoor picnic area & \multirow{6}{*}{$\begin{array}{c}\text { parties and } \\
\text { social gathering }\end{array}$} & \multirow{6}{*}{$\begin{array}{l}\text { to gather with friends, taste local } \\
\text { food, and buy souvenirs }\end{array}$} & \multirow{6}{*}{$\begin{array}{l}\text { to increase the popularity of the farm and attract } \\
\text { tourists to buy farm products }\end{array}$} & \multirow{6}{*}{$\begin{array}{l}\text { a. developing food therapy with local ingredients } \\
\text { b. cultural and creative gifts } \\
\text { c. innovative packaging of farm products } \\
\text { d. developing products which can be transported by express } \\
\text { e. delivery service }\end{array}$} \\
\hline & BBQ area & & & & \\
\hline & camping & & & & \\
\hline & outdoor selling area & & & & \\
\hline & theme restaurants & & & & \\
\hline & gift stores & & & & \\
\hline
\end{tabular}


Table 2. Cont

\begin{tabular}{|c|c|c|c|c|c|}
\hline & Touchpoints & Visiting Motivations & Tourists' Needs and Expectations & Goals of Touchpoints & Innovative Design of Opportunity Points \\
\hline & exits/parking lots & \multirow{4}{*}{$\begin{array}{l}\text { word of mouth and } \\
\text { recommendations } \\
\text { to others }\end{array}$} & to leave with satisfaction & $\begin{array}{l}\text { to guide tourists with professional signs and hopefully } \\
\text { their positive comments may attract more visitors }\end{array}$ & giving tourists cards or little souvenirs as gifts \\
\hline \multirow{3}{*}{ post-service } & online stores & & \multirow{3}{*}{$\begin{array}{l}\text { to get relaxed both physically } \\
\text { and mentally }\end{array}$} & \multirow{3}{*}{$\begin{array}{l}\text { to let tourists buy more farm products and } \\
\text { recommend the farm to more people }\end{array}$} & \multirow{3}{*}{$\begin{array}{l}\text { a. mature online stores } \\
\text { b. creating an online platform for tourists to write comments and encouraging } \\
\text { them to write positive comments using gift stimulation }\end{array}$} \\
\hline & online comments & & & & \\
\hline & $\begin{array}{l}\text { word of mouth: } \\
\text { recommending others to } \\
\text { the farm }\end{array}$ & & & & \\
\hline
\end{tabular}




\section{5 Meanings of the Service Design of Leisure Farms}

The framework of leisure farms' service design proposed in this study combines the tourist touchpoints applicable to most leisure farms and the core motivations of tourists to visit leisure farms, and creates an innovative design of touchpoints through the interaction between the demands and expectations of tourists and the goals of touchpoints.

Through the above stages, we have found a sustainable development method for the agricultural tourism of leisure farms. However, currently, this study is mostly based on the authors' idealized hypothesis. In practical operation, it may cause problems and call for improvement due to customers' different thinking patterns and ways of expression.

Table 2 shows the model framework for the overall thinking pattern of leisure farms' innovative service design. Customers' CJM touchpoints before, during, and after service on leisure farms are displayed on the vertical axis, while their motivations and expectations on each touchpoint, farm operators' business objectives of touchpoints, and opportunity innovation are based on tourists' corresponding motivations and displayed on the horizontal axis. For example, as mentioned in the study of core motivations above, word of mouth (recommendation by others), online information, and customer service on the telephone before service are the main source for people to know the farm. Also, that "the farm earns a very good reputation and my friends and families recommend me to go there" is the core motivation for visiting a leisure farm. Therefore, the customers' motivation represented by these three touchpoints is recommendation. The customers' expectation on these touchpoints is to find a suitable farm for holiday quickly. Meanwhile, for the marketing team, these three touchpoints mean to stimulate customers' decisions to visit the farm with high expectations. For the innovative design of touchpoints, we have come up with several recommendations based on the goal of "making customers decide to visit the farm and look forward to that": a. create an online application; $b$. encourage people to share their visiting experiences on social media; $c$. create a medium for sharing experience; $d$. provide a farm map and sufficient information on the website. As experiencers, customers are the best carrier of marketing, and online tools such as new media are the best way of presentation and advertising.

For example, the three touchpoints of photograph shooting area, recreational pavilion, and landscaping design during the service means "appreciating countryside scenery, having rest, and relaxing yourselves" as visiting motivations, so the corresponding tourists' expectations on the horizontal axis are hoping to relieve the stress, relax, and have unforgettable memories. Through tourists' interaction with these three touchpoints, farm operators' goals should be letting tourists advertise for them on social media and increasing the farm's popularity, based on which we propose some suggestions on the direction of innovative service design: provide more seats for rest, add interactive devices, implant the farm brand into people's minds subtly, and increase the farm's popularity on social media. Meanwhile, it increases the possibility of the farm being known by more potential customers through social media, which triggers the visit of new customers and increases the revisit of previous customers.

The touchpoint target tools give farm operators and staff a clear and consistent direction on farms' innovative service design, which eliminate the need to match lines in previous touchpoint blueprints or matrices so that farm operators can work on the new direction of innovative service design and do targeted design based on opportunity points requiring innovation. The farm operators and staff can be guided in their work, so as to better serve the overall operation of leisure farms.

In the competition among leisure farms, it is quite essential to let customers decide to visit quickly and recommend the farm to more friends after the pleasant journey. In a Harvard Business Review article "What is a Strategy", it is clearly stated that "the essence of strategy is to be different from your rivals" [26]. Dhebar proposed five requirements in the touchpoint study: 1 . the quality should be guaranteed as committed; 2 . easy to access and available; 3 . good guiding experience; 4 . worthy of recommendation; and 5. different strategies [27]. It is critical that touchpoints at different stages of farm experience should be strategically different, and the touchpoint framework must be strategically 
different from that of other competitors. Understanding the attractive points of a leisure farm which lead tourists to visit, revisit, or recommend to others is an essential element in developing a successful farm tourism strategy and achieving a targeted marketing strategy. This study combines tourists' core motivations with touchpoint goals to propose an innovative strategic framework for the five directions of leisure farm service design.

\subsection{Good Carrier for Word of Mouth}

Word of mouth (recommendation from and to others) is an essential touchpoint in service design both before and after the service on leisure farms. A study of German tourists shows that tourists believe in the comments by other tourists more than the advertisement of travel agencies. $95 \%$ of tourists believe that online comments are trustworthy, and $65 \%$ of them will check the comments on different websites [28] before booking a trip. The questionnaire of tourists' core visiting motivations shows that friends and families' recommendation and websites are the main two sources for tourists to get information about leisure farms. They spend not only money but also their valuable holiday time. Therefore, trust in tourism brands and their products is the most important factor. Memories of good travel experience can generate word of mouth, which can be of great influence through social media and travel comment websites [24]. This is the requirement that the quality should be guaranteed as committed and be worthy of recommendation in Dhebar's study. When setting touchpoints, improving the dissemination ability of its contents can be conducive to customers' voluntary recommendations to others, which is also one of the methods to further enhance the effect of word-of-mouth.

As one type of word of mouth reference, customers' online comments are an important factor which affects a customer's decision to visit the farm. According to Chen and Xie's research, online customer feedback is a kind of information product created by users based on personal experience, which can be used as a new element of the marketing mix and can be regarded as a free "sales assistant" to help customers identify the product they want most [27]. Additionally, a "sales assistant" may recommend products and services that are tempting and attractive but not so important to new customers, which enriches the contents of leisure farms and makes the dissemination of leisure farms more reliable. Therefore, it is especially important to establish and maintain a social group for tourists to interact with each other based on word of mouth before and after service, which can increase the number of loyal customers and explore new ones. In the strategic and innovative design of touchpoints for word of mouth, online information and farm websites serve as the first channels to show the farm brand and present the attractiveness of the farm to tourists, and they are also touchpoints where tourists may have interactions with leisure farm operators after their visit. Proper and optimal use of online tools for advertisement is strategically significant to the establishment of a leisure farm marketing matrix.

Internet-based contents of dissemination should include farm information, maps, surrounding environment, routes, activity information, medical information, online shopping malls, etc. The popularity of mobile devices has made it easier for customers to access and communicate than before, especially when designing comment sections on social media to encourage tourists to share their visiting experience with others. Creating an integrated website of information about the farm is an important part of service design that attracts visitors to the farm, and it is also an important channel for information dissemination, event announcement, and farm service. Therefore, a clear and simple online service channel is undoubtedly necessary. For the online shopping mall of leisure farms, it is an important path to recall customers' memories and an important channel to introduce the farm to potential customers. Therefore, it needs to meet the demands of previous tourists and attract potential customers, so that it can play a role in both the post-travel stage of previous customers and the pre-travel stage of potential customers. The online shopping mall should be easy to access and one should be able to easily check the bill, so that visitors can view products and conduct purchases after leaving the farm, such that the online shopping mall provides multi-functional services and becomes a channel with which customers can interact independently outside the leisure farm. Additionally, 
the comments and feedback on the products in the online shopping mall also have referential value for the development and optimization of the leisure farm's products and services.

\subsection{Enough Space for Rest}

Getting close to nature, rest, and relaxation are the primary motivations for tourists to visit leisure farms. They choose to stay on a farm for four hours or even overnight. It is the focus of service innovation to let tourists get enough rest and relaxation within limited time while not feeling boring and share their happy memories with others. On a leisure farm, ways to relax can be various and impressive, which include tasting delicious food or having a deep understanding of the farm and life on the farm: a restaurant, an outdoor sitting place like stone piers and wooden boards, a cup of tea in the cabin, relaxation in the spa pool, the flavor of farm fruit, an attentive yoga class, a 15-minute meditation, etc. Leisure farm operators can design both dynamic and static activities according to different farm themes. "Resting" is not a completely static concept; it is more about psychological relaxation and spiritual pleasure, so the rest area of leisure farms should be paid more attention to the comfort it can bring, and then the entertaining and sharing elements, which is more conducive to the overall management of leisure farms.

The setting of rest area has a direct impact on customers' experience, and their visiting experience on the farm may influence customers' purchasing decision. In the design of rest facilities, it is necessary to ensure that tourists spend more time to relax themselves. The touchpoint goal of resting area space is to meet tourists' expectation of having a good rest. It is necessary to meet customers' demands on private time and space and consider the possibility of customers participating in group activities and ways of relaxation in those activities. Tourists can slow down and enjoy the quiet atmosphere, culture, and aesthetic design on the farm during relaxation hours. Farm operators hope that tourists can remember these touchpoints and recommend the farm to others so as to increase the popularity of the farm and bring more tourists to the farm. Photographs posted on social media is the best way to improve a farm's word of mouth.

\subsection{Local Food on the Farm}

Visiting leisure farms to taste local food is another motivation following the relaxation one, and food is tourists' first concern in the questionnaire on factors that people pay most attention to of a farm. The desire for food and the judgment of food are often human instincts, so food has become an important factor to impress customers during the visit on leisure farms. The results of Choe and Kim's research demonstrated that tourists' attitude toward local food positively affects food destination image [29]. Alderighi, Bianchi, and Lorenzini also pointed out that strong appreciation for a local food specialty has a positive effect only on the intention to (re)visit the place of origin [30]. Moreover, in recent years, more and more scholars and industries are paying attention to food in tourism research, which shows the importance of food in destination tourism, especially on the farm. The judgment of the food on leisure farms is different from that of other tourist attractions, as more attention is paid to the characteristics of the food itself and the local culinary method. It will be a key factor to affect tourists' positive attitude towards the farm or prompt tourists to book a revisit. Tourists enjoy special local food made of fruits and vegetables grown on the farm and meat from stocks raised on the farm, especially the unique local recipes which are different from those in urban restaurants.

Innovation of farm food can be sought in farm products or local specialties. For example, on a strawberry farm, research and development of recipes can be conducted to provide strawberry cake, strawberry pizza, chicken legs in strawberry sauce, strawberry biscuits, etc., and all recipes can be related to strawberries. Furthermore, research and development of local food can involve creative food therapy, local specialties, and food recipes using local Chinese herbal medicine, which enhances the distinctive impression of the food and impresses tourists by providing them with relaxation time and healthy diets. In particular, the farm can develop food products with quality guarantee period and quick transportation. Together with the delivery service and takeout service, tourists will find it 
convenient to purchase food products and make online orders after leaving the farm. In this way, the farm can be more profitable.

\subsection{Interaction and Knowledge Acquisition}

In Ryff's research on psychosocial happiness, there are six dimensions, including personal growth, self-acceptance, environmental control, positive relationship with others, autonomy, and life goals [31]. Participation in leisure activities can increase the sense of happiness by gaining sense of balance, new opportunities, and feelings of belonging and improving self-awareness, social connection, and desire for control [32-34]. The core factor of participation is to build an interactive mode. Interaction is a process of communication among people, and it exists in all kinds of social activities. However, in leisure agriculture projects, tourists often unconsciously join the interactive activities because it has a relatively relaxed and relieved atmosphere, which is different from other interactive forms and can strengthen the relationships among people and between tourists and farms. The interactive activities on the farm can enhance the social relationships of the tourists, which enables people to enter the "social circle" without being defensive and can also attract more tourists through the social circle. The farm should provide tourists with a variety of innovative activities to fulfill their interests, prolong their stay hours, and impress them greatly so that they will recommend the farm to friends and families, and the farm can gain more popularity [35]. On the other hand, the farm is regarded as a social scene, and the experience obtained on the farm is used as the core of information exchange, which is more conducive to the collection of customers' opinions and suggestions for leisure farms. At the same time, the farm becomes a part of their social interaction, which makes the dissemination of information about the farm in social media more natural and truer.

Leisure activities can further meet customers' demands on relaxation. Leisure activities can stimulate heart beating when people are experiencing challenging tasks equal to or beyond their ability, which gives them a sense of internal happiness [36]. After entering the farm, tourists are exposed to new knowledge. They can learn cultural customs, planting techniques, animal raising skills, and knowledge about climate and solar terms on the farm, which expands their cognitive boundaries. The acquisition of new knowledge in such a stress-free environment offers tourists more obvious pleasure both physically and mentally.

\subsection{Differentiated Design}

Kirillova et al. pointed out that the uniqueness of destination can have short-term and long-term effects on tourism behavior [37]. The aesthetic characteristics of the destination are influential in not only evaluating the overall consumer experience, but also stimulating consumption decisions (including the time of stay) [33]. Operators should combine the rural culture with the farm's unique characteristics, make full use of the unique agricultural resources in the countryside, and create an impressive farm brand using the unique seasonal, biological, and practical elements on the farm. They also need to design stylized parking lots, innovative package of agricultural products, cultural and creative gifts with farm characteristics, personalized sanitary facilities, and warm accommodation spaces to stun tourists through their senses of vision, audition, olfaction, taste, and touch in order to make them loyal fans to the farm.

From the perspective of marketing, leaving a deep impression on customers is only the basic step. Instead, generating value from customers is the meaning of marketing. Previous research studies have shown that personalized settings can make customers become loyal fans of the farm. Based on human beings' nature of sharing information with others, tourists can share what they have seen and heard on the farm to others through social media, which will attract more potential tourists and gain more opportunities for seeking new tourists and value multiplication. Tourists' sharing to third parties contains their true feelings and real experiences, so it is more convincing. The online mall can also be a channel for tourists to get information about the farm after the visit and service for tourism products; it enhances the sense of participation and delivers relevant information to the third party 
through words and pictures. Regarding visitors' information sharing with the third party as a channel of marketing is also an effective way to further promote the marketing and management of leisure farms and achieve marketing goals.

\section{Discussion: Open Innovation in the Service Design of Leisure Farms}

In the information age, the service design of leisure farms only relies on the farms' internal resources for innovative activities, and it has been difficult to adapt to the rapidly developing tourism market demand and the increasingly fierce competition among enterprises. Under such circumstances, the "open innovation" of the service design of leisure farms should be regarded as the dominant way of innovations on the business model of leisure farms.

Based on all the touchpoints in the customer journey map of leisure farms and the direction of the key service design innovation derived from tourists' visiting motivations before, during, and after the trip and the demands and expectations of the tourists which fulfill the touchpoints of tourists' experience, it is possible to form an innovative design of opportunity points that the decision makers of leisure farms need to carry out. The entire process needs to balance the internal and external resources for innovation in the service design of the farm, which requires the establishment of close connection between leisure farms and all stakeholders in order to achieve the sharing of innovation elements among local enterprises, employees, and tourists as well as open innovation, integration, and network sharing.

The innovation of touchpoints in leisure farms is mainly based on individual behaviors. By analyzing the stages before, during, and after visiting leisure farms, we find ways to realize touchpoint innovations. This is an innovative design based on the context in which consumers' behavior and consuming behavior occur.

\subsection{Touchpoint Innovation before Service}

Before the service, the development of online applications enables tourists who have completed the trip to share their experience with others on social media, which develops media for sharing experience and improves the customer journey map and travel route planning. This design mainly relies on people's dependence on the Internet and social media to make the sharing of travel experience a spontaneous behavior. The information about leisure farms is released by real experiencers without target readers to attract more people to the farm, which is how the Internet is involved in the operation and management of leisure farms.

\subsection{Touchpoint Innovation during Service}

The innovation of touchpoints during service is mainly conducted based on the leisure purposes that tourists want to achieve on leisure farms, which are set up with various demands in the leisure process. At this stage, leisure farms may cooperate through external resources to achieve win-win cooperation. Through establishing the touchpoints which meet the tourists' demands on travel experience and the sharing system that satisfies the related stakeholders, visitors are able to spontaneously enter the touchpoints of travel routes and stops set by leisure farm operators. That is to say, the arrangement of leisure farm operators becomes the travel demand of tourists, so that leisure farms can better serve the tourists and convey the information that the farm operators want tourists to know.

\subsection{Touchpoint Innovation after Service}

The innovation of touchpoints after service is mainly to recall the visitors' memories and trigger revisits, which still uses the Internet as a carrier. Through e-commerce and personal experience sharing, the contact line between leisure farms and tourists is extended, so as to achieve the purpose of the post-service stage. 


\section{Conclusions and Limitations}

\subsection{Implication}

This paper proposes a method of integrating customers' core motivations, touchpoints, and new touchpoint target tools into the customer journey map through innovative thoughts, methods, and tools of service design, showing farm operators ways to create and implement the innovative service design of touchpoints. Combined with tourists' core visiting motivations, we have proposed five strategic developing directions for the service design of leisure farms in terms of appropriate resource deployment of the marketing mix: a platform for good word of mouth, sufficient rest areas, local farm food, interaction and knowledge acquisition, and differentiated design. The five strategic initiatives help farmers break down industry barriers, provide them with more suitable solutions, and advise them on sustainable business models of leisure farms.

In the use of the touchpoint target tools, the cross-functional team can develop a strategic approach to leisure farms' touchpoints based on the goal of consistency to improve the experience of touchpoints. The thinking patterns of this kind of service design allow leisure farm operators to develop and present more innovative, public-friendly, and effective solutions to complex behavioral, social, and economic issues. This is an innovative framework of service design which is applicable for most leisure farm operators. Particularly, it is one of the few studies on the relationship between small and medium-sized enterprise management and service design in the highly competitive agricultural tourism industry. Small and medium-sized leisure farms have a limited budget on product development and advertisement, so farm operators are facing both opportunities and challenges. Such farms are burdened with strong responsibilities as family businesses and adopt flat management, and these are excellent preconditions for innovation. According to the certain style of a farm, its operators can vertically innovate on some touchpoints such as catering or leisure areas. Large-scale agricultural tourism enterprises can make horizontal innovations through creating more touchpoints.

\subsection{Limitation and Future Research Topics}

There are some limitations in this study. We only took the service design of leisure farms as the research object and came up with touchpoints to solve key problems for the purpose of improving the management of leisure farms. First, this study only took leisure farms in Taiwan as the research object, and the characteristics of leisure farms in other regions need to be taken into consideration in the future. Second, this study focuses on the role of leisure farm managers and tourists without fully considering the synergy among other stakeholders of leisure farms, as well as the interactions among other participants in the setting and the triggering process of touchpoints in this research. Future research and studies may be conducted from the perspective of multi-party collaboration. Last, but not least, this study does not include an innovative analysis of the touchpoints of different tourist groups. In future research, different service designs for different tourist groups can be employed, for example, to analyze the situation when a family or a tourist group visits the farm and provide innovative service design, respectively.

Author Contributions: Conceptualization, M.L. and Z.J.; methodology, F.-Y.L.; investigation, M.L.; resources, F.-Y.L.; data curation, M.L. and Z.J.; writing—original draft preparation, M.L.; writing—review and editing, M.L. and Z.J.; and visualization, M.L. All authors have read and agreed to the published version of the manuscript.

Funding: This research received no external funding.

Conflicts of Interest: The authors declare no conflict of interest. 


\section{References}

1. Busby, G.; Rendle, S. The transition from tourism on farms to farm tourism. Tour. Manag. 2000, 21, 635-642. [CrossRef]

2. Barbieri, C.; Mshenga, P.M. The role of the firm and owner characteristics on the performance of agritourism farms. Sociol. Rural. 2008, 48, 166-183. [CrossRef]

3. Sharpley, R.; Vass, A. Tourism, farming and diversification: An attitudinal study. Tour. Manag. 2003, 27, 1040-1052. [CrossRef]

4. Fadden, T.M.; Gorman, M. Exploring the concept of farm household innovation capacity in relation to farm diversification in policy context. J. Rural Stud. 2016, 46, 60-70. [CrossRef]

5. Domenico, M.D.; Miller, G. Farming and tourism enterprise: Experiential authenticity in the diversification of independent small-scale family farming. Tour. Manag. 2012, 33, 285-294. [CrossRef]

6. Prendeville, S.; Bocken, N. Sustainable Business Models through Service Design. Procedia Manuf. 2017, 8, 292-299. [CrossRef]

7. Hjalager, A.M. A review of innovation research in tourism. Tour. Manag. 2010, 31, 1-12. [CrossRef]

8. Fuglsang, L.; Nordli, A. On Service Innovation as an Interactive Process: A Case Study of the Engagement with Innovation of a Tourism Service. Soc. Sci. 2018, 7, 258. [CrossRef]

9. Park, J.; Jeong, E. Service Quality in Tourism: A Systematic Literature Review and Keyword Network Analysis. Sustainability 2019, 11, 3665. [CrossRef]

10. Beard, J.G.; Ragheb, M.G. Measuring leisure satisfaction. J. Leis. Res. 1980, 12, 20. [CrossRef]

11. Buckley, R. Ecotourism: Principles and Practices; CABI: Wallingford, UK, 2009.

12. Jeon, Y. Problem-Solving Design-Platform Model Based on the Methodological Distinctiveness of Service Design. J. Open Innov. Technol. Mark. Complex. 2019, 5, 78. [CrossRef]

13. Stickdorn, M. Tourism and service design thinking: Who learns from whom? Touchpoint 2012, 4, 58-61.

14. Rosenbaum, M.S.; Otalora, M.L.; Ramírez, G.C. How to create a realistic customer journey map. Bus. Horiz. 2016, 60, 143-150. [CrossRef]

15. Ortbal, K.; Frazzette, N.; Mehta, K. Stakeholder Journey Mapping: An Educational Tool for Social. Entrep. Procedia Eng. 2016, 159, 249-258. [CrossRef]

16. Stickdorn, M.; Schneider, J. This is Service Design Thinking: Basics, Tools, Cases; John Wiley \& Sons Inc.: Hoboken, NJ, USA, 2012.

17. Dhebar, A. Toward a compelling customer touchpoint architecture. Bus. Horiz. 2013, 56, 199-205. [CrossRef]

18. Ma, A.T.H.; Chow, A.S.Y.; Cheung, L.T.O.; Lee, K.M.Y.; Liu, S. Impacts of Tourists' Sociodemographic Characteristics on the Travel Motivation and Satisfaction: The Case of Protected Areas in South China. Sustainability 2018, 10, 3388. [CrossRef]

19. Ryan, C. Learning about tourists from conversations: The over-55s in Majorca. Tour. Manag. 1995, 16, 207-215. [CrossRef]

20. Yoon, Y.; Uysal, M. An examination of the effects of motivation and satisfaction on destination loyalty: A structural model. Tour. Manag. 2005, 26, 45-56. [CrossRef]

21. Mei-Jung, L.; Wei-Cher, W. The Study on Visitors' Cognition and Experience to the Leisure Agriculture. J. Outdoor Recreat. Study 1999, 12, 19-40.

22. Juho, P.; Raija, K. Rural Wellbeing Tourism: Motivations and Expectations. J. Hosp. Tour. Manag. 2010, 17, 150-157.

23. Iso-Ahola, S.E.; Allen, J.R. The Dynamics of Leisure Motivation: The effects of outcome on leisure needs. Res. Q. Exerc. Sport 1982, 53, 141-149. [CrossRef]

24. Baloglu, S.; McCleary, K.W. A model of destination image formation. Ann. Tour. Res. 1999, $26,868-897$. [CrossRef]

25. Lin, M.; Li, F.-Y.; Zhe, J. A Study on the Plan and Design of Leisure Farms' Tourist Touch Points. Acad. J. Humanit. Soc. Sci. 2020, 3, 65-77.

26. Porter, M. “What Is Strategy?". Harv. Bus. Rev. 1996, 74, 61-78.

27. Chen, Y.; Xie, J. Online Consumer Review: Word-of-Mouth as a New Element of Marketing Communication Mix. Manag. Sci. 2008, 54, 477-491. [CrossRef]

28. IUBH. Untersuchung der Bedeutung $\mathcal{E}$ Glaubwürdigkeit von Bewertungen auf Internetportalen; International University of Applied Sciences Bad Honnef: Bad Honnef, Germany, 2011. 
29. Choe, J.Y.; Kim, S. Effects of tourists' local food consumption value on attitude, food destination image, and behavioral intention. Int. J. Hosp. Manag. 2018, 71, 1-10. [CrossRef]

30. Alderighi, M.; Bianchi, C.; Lorenzini, E. The impact of local food specialities on the decision to (re)visit a tourist destination: Market-expanding or business stealing? Tour. Manag. 2016, 57, 323-333. [CrossRef]

31. Ryff, C.D. Happiness is everything, or is it? Explorations on the meaning of psychological well-being. J. Personal. Soc. Psychol. 1989, 57, 1069-1081. [CrossRef]

32. Lloyd, K.; Little, D. “Quality of life, aren't we always searching for that?": How women can achieve enhanced quality of life through participation in outdoor adventure recreation? J. Can. Assoc. Leis. Stud. 2005, 29, 147-180. [CrossRef]

33. Lusby, C.; Anderson, S. Community and quality of life: The case of ocean cruising. World Leis. J. 2008, 50, 232-242. [CrossRef]

34. Mactavish, J.; Kelly, J.; Mackay, K.J.; Iwasaki, Y.; Betteridge, D. Family Caregivers of Individuals with Intellectual Disability: Perspectives on Life Quality and the Role of Vacations. J. Leis. Res. 2007, 39, 127-155. [CrossRef]

35. Adongo, C.A.; Badu-Baiden, F.; Boakye, K.A.A. The tourism experience-led length of stay hypothesis. J. Outdoor Recreat. Tour. 2017, 18, 65-74. [CrossRef]

36. Bryce, J.; Haworth, J.T. Wellbeing and flow in sample of male and female office workers. Leis. Stud. 2002, 21, 249-263. [CrossRef]

37. Kirillova, K.; Fu, X.; Lehto, X.; Cai, L. What makes a destination beautiful? Dimensions of tourist aesthetic judgement. Tour. Manag. 2014, 42, 282-293. [CrossRef]

(C) 2020 by the authors. Licensee MDPI, Basel, Switzerland. This article is an open access article distributed under the terms and conditions of the Creative Commons Attribution (CC BY) license (http://creativecommons.org/licenses/by/4.0/). 